\title{
Thermal processes under explosive loading of amorphous alloy powders
}

\author{
Yury Voloshin ${ }^{1 *}$, Ruslan Zhemukhov ${ }^{1}$, and Marina Zhemuhova ${ }^{1}$ \\ ${ }^{1}$ Kabardino-Balkar state University, Chernystevskiy str., 173, Kabardino-Balkarian Republic, \\ Nalchik, 360004, Russia
}

\begin{abstract}
The article deals with the state of production of bulk amorphous and nanocrystalline materials. Conditions for the preservation of the "Xray" amorphous state in compact materials obtained by explosive pressing of amorphous alloy powders are formulated. The two-front Stefan problem is solved and it is shown that the cooling rate of liquid layers on the contact surfaces of powder particles under explosive loading corresponds to the critical quenching rate of the formation of amorphous structures in metal alloys.
\end{abstract}

\section{Introduction}

Amorphous metals are a relatively new class of metallic materials, which were of great interest in the middle and end of the last century and have an extensive bibliography [1-7]. Obtaining the amorphous state of metals in the solid phase is associated with the achievement of very high cooling rates (on average $106 \mathrm{~K} / \mathrm{s}$ ), which is achievable in cross sections up to several tens of micrometers. Therefore, the main form of obtaining amorphous metals is thin tapes, powders or microwires. A number of papers present the results of obtaining compacts from amorphous alloy powders [8-12]. However, amorphous metals in the form of tapes, microwires and compacts have received limited practical use due to the low crystallization temperature and technological difficulties in manufacturing products of complex shapes.

Currently, there is an increased interest in materials with a nanocrystalline structure, for which there are no operational limitations inherent in amorphous metals [13-18]. One of the ways to obtain nanocrystalline structures is controlled crystallization of amorphous alloys [19-24], so it seems relevant to discuss the issues of preserving the amorphous state of compacts of amorphous alloy powders during shock-wave processing.

In [8], it is shown that when compacting dispersed media by the method of explosive pressing, due to the adiabatic nature of the process the entropy of the system increases and the powder body is heated. Estimates of the temperature averaged over the volume of the compressed dispersed medium for the thermodynamically equilibrium state behind the shock wave front [8] give temperatures up to $1400 \mathrm{~K}$. The upper temperature values exceed the crystallization temperature of most amorphous alloys (700 ... $800 \mathrm{~K})$, but the material remains "X-ray" amorphous, which is confirmed by Figure 1 [8].

*Corresponding author: author1 til4949@mail.ru 


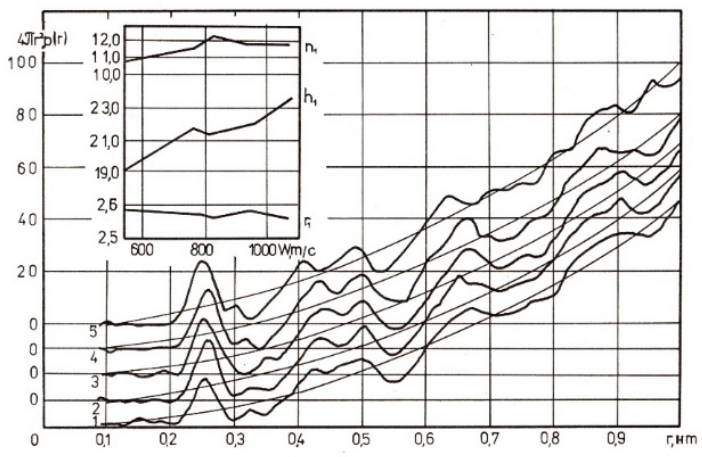

Fig. 1. The function of the radial distribution of atoms (FRRA)

$1-5$ - the explosive loading velocity of $560 \ldots 1070 \mathrm{~m} / \mathrm{s} ; \mathrm{r}_{1}-$ the radius of the first coordination sphere; $h_{1}$ - the height of the first maximum on the FRRA curve; $\mathrm{n}_{1}-$ the coordination number.

Based on the "X-ray" amorphous state of the alloy, it can be assumed that the main thermal processes of shock compression are concentrated on the contact surfaces of the particles, the connection of which is carried out by the mechanism of setting in the solid phase and through the formation of liquid layers. For the subsequent re-quenching of the liquid into an amorphous state, cooling rates of the order of $10^{6} \mathrm{~K} / \mathrm{s}$ are required. The melt cooling rate and the temperature distribution in the melt and the solid amorphous substrate can be estimated using the instantaneous source approximation, taking into account the heat release at the phase front [25].

\section{Setting the Research Task}

The problem can be formulated as follows: at time $t=0$, a layer of melt with a thickness of $2 \delta$ was instantly formed between the particles of the solid phase, at the same moment the propagation of the phase transformation front deep into the melt and the temperature front deep into the solid phase begins. The temperature distribution in the melt and the amorphous substrate is determined by the instantaneous heat source at the origin and the moving continuous heat sources at the phase front, i.e., the corresponding Stefan problem is formulated. When setting the problem, a number of assumptions are used: the ideal thermal contact at the substrate-melt interface; the problem is symmetric and heat propagation in the half-plane is considered; the thermophysical properties of the media are independent of time and temperature and are the same for the amorphous and liquid phases; the boundary effects can be neglected. Then, mathematically, the problem can be formulated by writing down the equation of thermal conductivity, the heat balance at the phase front $\mathrm{z}(\mathrm{t})$, and the boundary and initial conditions.

$$
\begin{aligned}
& \frac{\partial T}{\partial t}=a \frac{\partial^{2} T}{\partial x^{2}} ; t>0 ; x \geq 0 ; T(x, t)_{x \rightarrow \infty}=T_{0} ; \frac{\partial T}{\partial x}(0, t)=0 ; \\
& \frac{L \rho}{\lambda} \frac{d z}{d t}=\left.\frac{\partial t}{\partial x}\right|_{z}+0, t-\left.\frac{\partial T}{\partial x}\right|_{z}-0, t ; T(z, t)=T_{m} ; x \neq z(t) ;
\end{aligned}
$$

where a - coefficient thermal diffusivity $\left(a=20 \cdot 10^{-6} \mathrm{~m}^{2} / \mathrm{s}\right) ; \lambda-$ coefficient of heat conductivity $\left(\lambda=72 \mathrm{~W} /(\mathrm{m} \cdot \mathrm{K}) ; \rho\right.$ - density of the amorphous material $\left(\mathrm{p}=7,5 \cdot 10^{3} \mathrm{~kg} / \mathrm{m}^{3}\right) ; \mathrm{c}_{\mathrm{p}}$ - specific heat capacity $\left(\mathrm{c}_{\mathrm{p}}=0,48 \mathrm{~kJ} /(\mathrm{kg} \cdot \mathrm{K}) ; \mathrm{T}_{0}\right.$ - the initial temperature of the amorphous 
substrate $\left(T_{0}=293 \mathrm{~K}\right) ; \mathrm{T}_{\mathrm{m}}$ - the melting point $\left(\mathrm{T}_{\mathrm{m}}=1170 \mathrm{~K}\right) ; \mathrm{L}$ - the heat of the phase transition ( $\mathrm{L}=77,5 \mathrm{~kJ} / \mathrm{kg})$.

The calculations used data for an amorphous alloy of the composition $\mathrm{Fe}_{40} \mathrm{Ni}_{40} \mathrm{P}_{14} \mathrm{~B}_{6}$ (atomic percentages) obtained by crushing an amorphous tape.

\section{Discussion of the Results}

Due to the nonlinearity of the problem, an exact analytical solution of the heat equation with a moving phase transition front is obtained for a number of the simplest cases, but even in these cases the solution is expressed by infinite series or special functions. Therefore, we used a numerical finite difference method with a combination of sequential determination of boundary conditions at the phase front and the run-through method. The variable values were the initial temperature and the thickness of the melt zone. Fig. 2,3 show the individual results of the calculation.

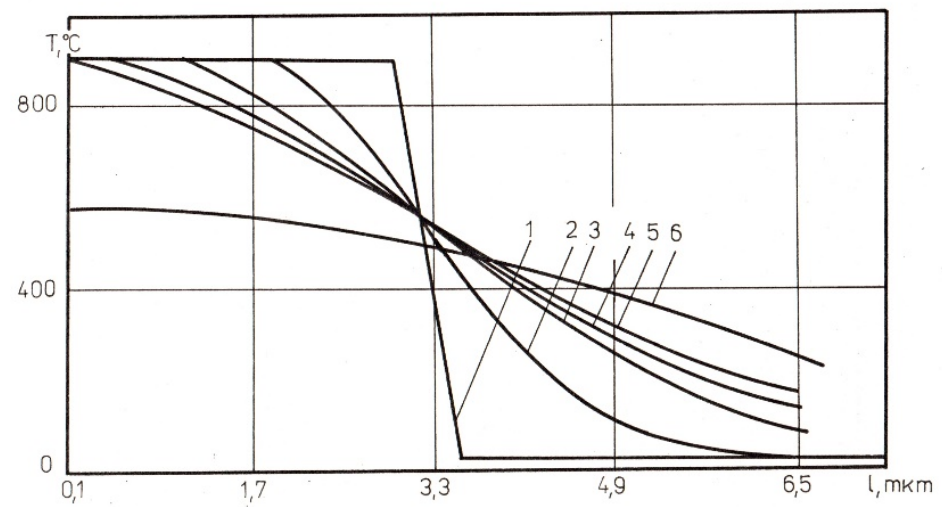

Fig. 2. Temperature distribution in the melt and the amorphous substrate (the half-thickness of the melt layer $\delta=3$ microns, the initial temperature of the melt $-\mathrm{T}_{\mathrm{r}}=1173 \mathrm{~K}$; the substrate $-\mathrm{T}_{0}=293 \mathrm{~K}$ ). 1-6: $\tau=0 ; 0,31 ; 0,92 ; 1,5 ; 2,0 ; 4,5$ microseconds, respectively.

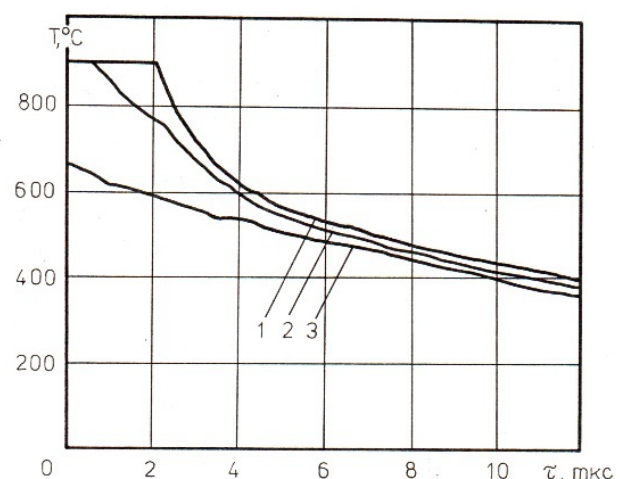

a)

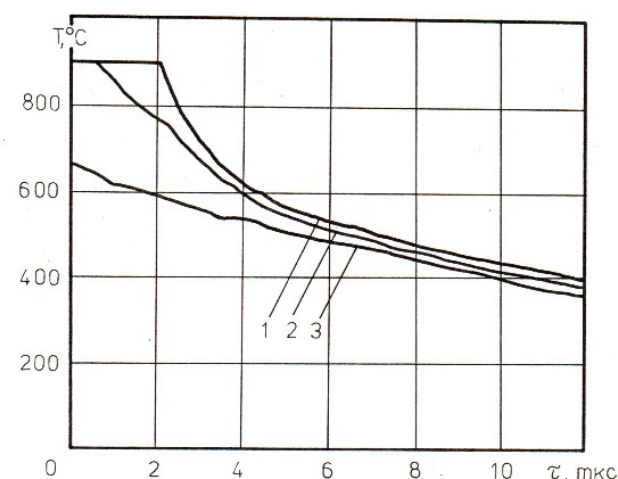

b)

Fig. 3. a - temperature distribution in different parts of the melt $\left(\delta=3 \mathrm{~mm} ; \mathrm{T}_{\mathrm{r}}=1173 \mathrm{~K} ; \mathrm{T}_{0}=293 \mathrm{~K}\right)$; b - the rate of cooling of the melt $\left(\delta=1 \mathrm{~mm} ; \mathrm{T}_{\mathrm{r}}=1173 \mathrm{~K} ; \mathrm{T}_{0}=293 \mathrm{~K}\right), 1-\mathrm{x}=0 ; 2=0,5 \delta ; 3-\mathrm{x}=\delta$ 
Fig. 2 shows that up to a depth of 1,5 microns, the heating temperature of the amorphous substrate exceeds the crystallization temperature of the amorphous alloy $\left(t_{c r}=405^{0} \mathrm{C}\right)$. However, there are no signs of crystallization on the FRRA curves (Fig. 1), although there is some ordering of the structure in the form of an increase in the height of the first maximum $\left(\mathrm{h}_{1}\right)$ and an increase in the value of the coordination number $\left(\mathrm{n}_{1}\right)$. Such a result can be interpreted by a symmetric statement of the problem with the condition on the phase front $T(z, t)=T_{m}$ the temperature on the phase front is unknown and is in the $T_{c r}<T_{x}$ $<\mathrm{T}_{\mathrm{m}}$, and the condition on the phase front should have the form $\mathrm{T}(\mathrm{z}, \mathrm{t})=\mathrm{T}_{\mathrm{x}}$. In addition, the crystallization temperature of the amorphous alloy is not a constant value, but depends on the heating rate. When determining the crystallization temperature, the scanning microcalorimetry method is used, in which the heating rate does not exceed $100 \mathrm{~K} / \mathrm{min}$, which does not correspond to the heating rates under dynamic compression.

3 shows that the cooling rate of the melt exceeds $10^{6} \mathrm{~K} / \mathrm{s}$, therefore, there are conditions for re-quenching the liquid layers into an amorphous state. As you move away from the solid substrate, the cooling rate decreases (Figure 3a), but still exceeds the critical speed. The discontinuity of the cooling curves in Fig. $3 \mathrm{~b}$ indicates that the phase front has reached the upper point of the melt layer, the heat generation at the phase front has stopped, and the cooling rate has increased. The most important factor, all other things being equal, is the nature of the thermal contact at the melt-liquid interface, which is ideally suited for the case under consideration. On the other hand, the solid substrate has the same chemical composition as the melt, which increases the chance of crystallization.

\section{Conclusions}

In general, the analysis of all the calculated data shows that up to half-thicknesses $\delta=20$ microns, the cooling rate at the thickness $\mathrm{x}=\delta$ is at the level of $10^{6} \mathrm{~K} / \mathrm{s}$ and the ratio of the melt thickness to the cooling rate is approximately 1:100. The initial temperature of the melt slightly reduces the cooling rate due to the heating of the solid substrate.

\section{References}

1. C. Suryanarayana, A. Inoue, Bulk Metallic Glasses (CRC Press, 2011)

2. F.C. Li, T. Liu, J.Y. Zhang, S. Shuang, Q. Wang, A.D. Wang, J.G. Wang, Y. Yang, Materialstoday ADVANCES, 4, 1-20 (2019)

3. A.B. Lysenko, I.V. Zagorulko, T.V. Kalinina, N.A. Kugay, Metallofiz. Noveishie Tekhnol., 40(1),1-21 (2015)

4. Yu. K. Kovneristy, Voluminously amorphizing metal alloys (Moscow, Nauka, 1999)

5. A.M. Glezer, N.A. Shurygina, Amorphous-nanocrystalline alloys (Fizmatlit, 2014)

6. V.A. Vasiliev et al. High-speed solidification of the melt (theory, technology and materials) (Moscow, Intermet Engineering, 1998)

7. V.K. Nosenko, A.Yu. Rudenko, T.N. Moiseeva, V.V. Maksimov, M. S. Nizameev, A.I. Limanovsky, A.M. Semirga, V.I. Weaver, Metallofiz. Noveishie Tekhnol., 37(12), 1681-1701 (2015)

8. O.V. Roman, A.P. Bogdanov, Yu.N. Voloshin, V. G Gorobtsov, I. M. Pikus Metallovedenie i termicheskaya obrabotka metallov, 10, 57-63 (1983)

9. V.F. Nesterenko, FGV, 22 (6), 85-98 (1985)

10. M.N. Voloshin, A.A. Novakova, A.I. Markov, G.V. Sidorova, G.A. Sirotina, V.P. Alyokhin, Physics and Chemistry of Material Processing, 5, 118-124 (1990) 
11. A.A. Bondarenko, S.I. Zolotorev, V.P. Kirko, A.V. Kleshchev, S.A. Lobasov, L.S. Tarasova, S.A. Khramenko, M.Yu. Izvitsky, FGV, 5, 127-131 (1990)

12. V.A. Golubev, A.V. Strikanov, V.G. Bugrov, G.A. Potemkin, V.B. Kudelkin, A.V. Golubev, M.A. Mochalov, Proceedings of the RFNC-VNIIEF,13, 196-207 (2008)

13. H. Gleite, Acta mater, 48. 1-29 (2000)

14. P.A. Vityaz, N.A. Svidunovich, D.V. Kuis, Nanomaterial Science (Minsk, Higher School, 2015)

15. M. Saka (Ed.), Metallic Micro and Nano Materials (Springer, 2011)

16. V.E. Panin, V.E. Egorushkin, The Physics of Metals and Metallography, 110, 464-473 (2010)

17. A.G. Kolmakov, K.A. Solntsev, P.A Vityaz, A.F Ilyushchenko, M.L. Kheifets, S. M. Barinov, Material Science, 9, 37-45 (2012)

18. M.I. Alymov, Powder metallurgy of nanocrystalline materials (Moscow, Nauka, 2007)

19. P.A. Gamov, A.D. Drosin, M.V. Dudorov, V.E. Roshchin, Metals, (6), 101-105 (2012)

20. V.V. Vavilova, V.T. Zabolotny, V.P. Korneev, M.O. Anosova, Metals, 2, 68-76 (2015)

21. V.V. Vavilova, V.P. Korneev, M.O. Anosova , Metals., 5, 47-54 (2016)

22. N.F. Shkodich, A.S. Logachev, S.G. Vadchenko, I.D. Kovalev, A.A. Nepapushev, S.S. Ruvimov, A.S. Mukasyan, Izvestiya vuzov. Poroshkovaya metallurgiya i funktsional'nye pokrytiya, 2, 14-21 (2017)

23. L. Junwei, L. Young, L. Shiqiang, W. Jun, G. Wenliang, Materials Letters, 294, 129761 (2021)

24. Z. Msetra, N. Khitouni, J.J. Suñol, M. Khitouni, M. Chemingui, Materials Letters, 292, 129532 (2021)

25. M.S. Kachan, V.N. Stern, FGV, 2, 119-126 (1979) 